\title{
Análise de custo horizontal e vertical
}

MAURÍCIO LINN BIANCHI - DiRETOR DE CONSTRUÇÃo

Boulevard Matarazzo

\section{INTRODUÇÃO}

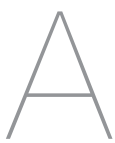

construção civil tem um legado de customização do

metro quadrado na área horizontal: levantam-se os custos, que são divididos por metro horizontal. O mercado evoluiu paradigmas precisam ser aprimorados, alinhando-se a novas necessidades de avaliação focada em tomadas de decisão.

Aliado à evolução da tecnologia, sistemas, e metodologia Executiva, $\mathrm{CH}$ (Custo Horizontal) e CV (Custo Vertical) merecem uma dicotomia na análise.

A Lei de Incorporação 4591 regula os registros de Incorporação nos Cartórios de Registro, dá fé pública. Segue critério de descrição da propriedade, áreas de usos comum e privativo, cobertas e descobertas, traduzindo para o papel aquilo

que se busca edificar e vender, abrindo um espaço para a identificação de custos diferenciados, valorizando locais, por exemplo, cobertos e descobertos. $\mathrm{Na}$ mesma linha, proponho uma evolução na análise real das construções.

Vamos abordar o tema da quantificação do metro quadrado horizontal e do metro quadrado vertical, buscando mitigar riscos na tomada de decisão, aumentando a assertividade nos custos e diferenciando o grau de dificuldade de execução, logística e prazos.

\section{CONCEITO BÁSICO DE CUSTO HORIZONTAL $\in$ VERTICAL}

Como podemos ver na Figura 1, temos 2 cenários com área horizontal de $1 \mathrm{~m}^{2}$, resultando em diferentes áreas verticais.

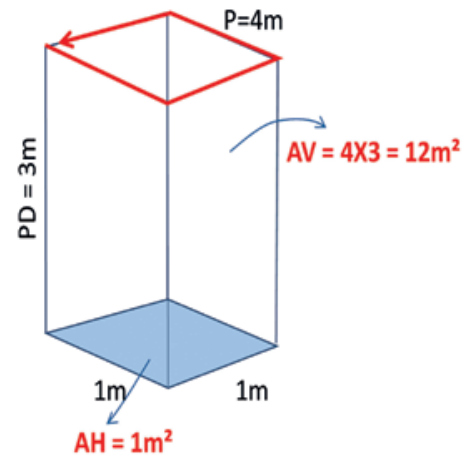

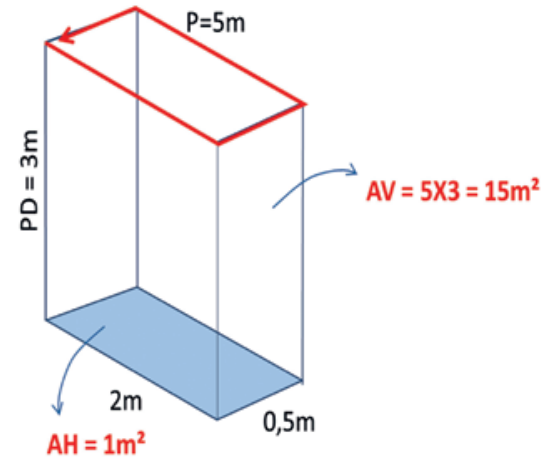

Figura 1

Cenários com mesma área horizontal e diferentes áreas verticais
Esta proposta é tão simples que chega a parecer óbvia, mas as empresas não montam suas matrizes de avaliação de custos em cima de premissas de custo de área horizontal e custo de área vertical.

O coeficiente de forma de um projeto precisa ser avaliado, pois leva a grande oscilação de custos, logística e prazos.

Vamos abordar a área de projetos, logística e metodologia executiva, considerando a análise volumétrica, para, na análise de Projeto, por exemplo, buscar avaliar o coeficiente de forma.

Duas construções com a mesma área útil e área total de construção, de mesma tipologia e memorial construtivo, apresentam oscilações de custo em função de seu coeficiente de forma, o que pode reduzir a margem do construtor ou do incorporador, gerando problemas à jusante, quando o mesmo já era conhecido à montante do projeto. São as famosas Gestões de Autopsia, expressão utilizada quando se descobre tardiamente um problema. Neste caso, é feita uma autopsia e, não havendo mais solução, reconhece-se o problema.

A visão de futuro acena para uma construção mais industrializada, uma redução na mão de obra intensiva, transferindo-a para o planejamento e os sistemas. Neste cenário, busca-se atingir, por exemplo, a produtividade de $25 \mathrm{HH} / \mathrm{m}^{2}$ e margem de $5 \%$ de variação de custo,, diferentemente da construção 
atual, com $40 \mathrm{HH} / \mathrm{m}^{2}$ e com perda dos conceitos de apropriação de custos.

A verticalização não onera, apenas requer a conceituação de "Projetar o Custo" e considerar o grau de dificuldade do projeto antes dele se materializar em canteiros.

\section{ANÁLISE DE CH E CV EM ESTRUTURAS EM CONCRETO}

Projetos são atualmente precificados com base em área estrutural, balizados na horizontal. Não são considerados o conceito de repetição, os níveis dos pavimentos, e que as atuais estruturas estão cada vez maiores e mais altas.

As estruturas de concreto armado têm preços que quase se igualam no mercado de Edificações Verticalizadas, sendo vendidas por volume, sem menção a CH (custo horizontal) e CV (custo vertical), que, muitas vezes, passam despercebidos e geram prejuízos ao contratado ou ao contratante.

Na Figura 2, o diagrama ilustra as fases de obrax prazos. Em vermelho, mostra-se um prazo maior na estrutura. Com base nisto, é preciso considerar que:

- As estruturas de concreto são o caminho crítico e podem ser executadas com qualidade, sem impacto no prazo final;

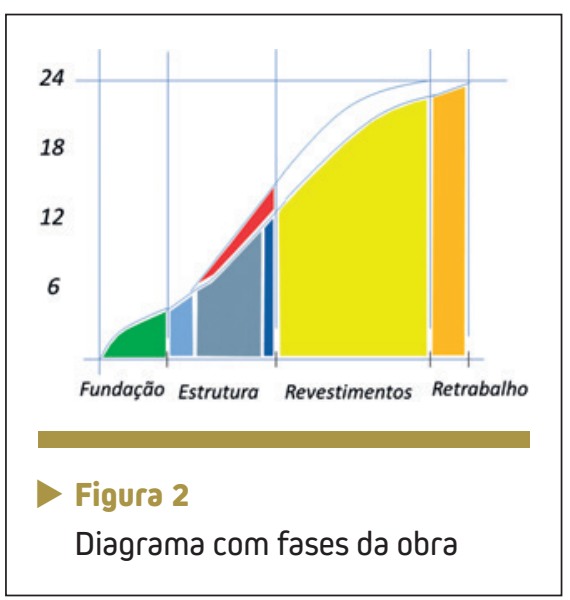

- $\mathrm{O} \mathrm{CH}$ e CV variam em suas tipologias e de acordo com a Arquitetura, gerando impactos diferentes;

- Custos Verticais nas Estruturas são maiores do que os Custos Horizontais.

\section{ANÁLISE DE CH E CV EM ESTRUTURAS EM CONCRETO}

Quando contratamos uma estrutura de concreto por metro cúbico, estamos de forma direta nivelando o grau de dificuldade de seus diferentes tipos.

Quando o projeto não considera a diferença entre edificações de 12, 18 e 24 andares, nivela-se o seu grau de dificuldade, contratando-se por metro cúbico estruturas de concreto diferentes, que requerem serviços diferenciados.

Não se propõe que seja aumentado o valor final da estrutura de concreto, mas apenas que seja diferenciada a alocação de custos em seu projeto, compensação que permite haver equilíbrio nos contratos, para quem paga a conta (em geral, os contratantes, e quando não, as empreiteiras de estrutura, que quebram antes de concluir a estrutura de concreto).

O concreto por metro cúbico de laje de subsolo pode custar o mesmo que o concreto por metro cúbico de uma laje no vigésimo andar de um edifício? Evidente que não, pois paga-se mais à etapa mais lucrativa do contratado quando não se considera o grau de dificuldade de todas as etapas da construção.

A armação de pilares de fundação e andares mais carregados pode ser paga pelo valor por quilo da armação dos pilares de andares mais elevados? Novamente, agindo assim paga-se mais ao trabalho mais lucrativo do contratado.

A montagem de forma de um pavimento em laje plana, com vigas robustas, pode ser paga por metro, tal como a montagem da forma de uma laje com jardineiras invertidas, com vigas pequenas e rebaixos? Neste caso, paga-se menos ao trabalho mais difícil do contratado.

Exemplos não faltam para distinguir $\mathrm{CH}$ e $\mathrm{CV}$ que justifiquem a merecida distinção de valores, pagando-se mais à medida que a gestão de custos para $\mathrm{H}$ e V apresente razões para tal aumento, o que criaria uma melhor gestão dos subcontratados e mitigaria o risco até o final de uma obra.

As estruturas das obras atuais são diferentes das do passado: um edifício antigamente era de 2 a 3 vezes menor em área e altura. Este problema de precificação precisa ser enfrentado por profissionais formados adequadamente e com discussões fomentadas por entidades de classe, como o IBRACON.

Vamos admitir que uma estrutura de concreto tenha um custo que represente aproximadamente $20 \%$ de uma construção. Nela, temos um custo horizontal e um custo vertical, e vale fazer menção que o horizontal é bem mais simples que o vertical , mas o mercado, sem perceber, faz pagamentos pelo mesmo valor às estruturas até atingirem o andar térreo, que acumula os grandes volumes de concreto, forma e aço, deixando um saldo de recursos menor proporcionalmente para executar a sua parte mais sensivel, que é a Vertical . De maneira geral, está convencionado um pagamento de uma estrutura por metro cúbico, sendo que o custo dos andares baixos é maior do que o de andares altos.

É comum ter mais de $50 \%$ do volume de concreto a ser lançado até o nível do primeiro piso, principalmente nos edifícios com subsolos, restando 50\% do volume para os andares superiores, onde a 
mão de obra é menos produtiva, mas os consumos por $\mathrm{kg} / \mathrm{m}^{2} / \mathrm{m}^{3}$ são menores.

Este debate ajudará na implantação de novas tecnologias e sistemas, de forma a tornar o mercado mais competitivo. Não podemos pagar o mesmo valor por metro cúbico a uma laje plana no térreo /subsolo e a uma laje em andares elevados, cuja área desenvolvida é, muitas vezes, 30\% maior que as lajes maiores citadas.

A implantação de uma visão de $\mathrm{CH}$ e CV poderá viabilizar que os subcontratados valorizem o uso de concreto autoadensável, gruas, telas, peças pré-cortadas e montadas, sendo pertinente ao convencimento dos executores de estruturas.

\section{PLANEJAR ETAPAS DE ACABAMENTO DE CIMA PARA BAIXO OU DE BAIXO PARA CIMA?}

O transporte vertical, a subida de pessoas e de materiais, merece reavaliação e quebra de paradigmas, com a conceituação do CV, para a redução de sua perda de eficiência (Figura 3).

\section{ANÁLISE DE CH E CV EM SOLUÇÕES ESTRUTURAIS}

Nas obras de subsolos/enterradas, as soluções e metodologias são absolutamente impactantes na matriz de custos e merecem destaque diferenciado, com os projetos contemplando as análises de $\mathrm{CH}$ e $\mathrm{CV}$, pois a decisão faz parte do sucesso do empreendimento.

No exemplo das Figura 4 e Tabelas 1 a 4, há uma análise de uma construção que poderia estruturar 33\% ou $21 \%$ da área construída abaixo do nível da Rua.

A decisão de custo simples por metro quadrado $(\mathrm{CH})$ leva à solução de executar 33\% de construção abaixo

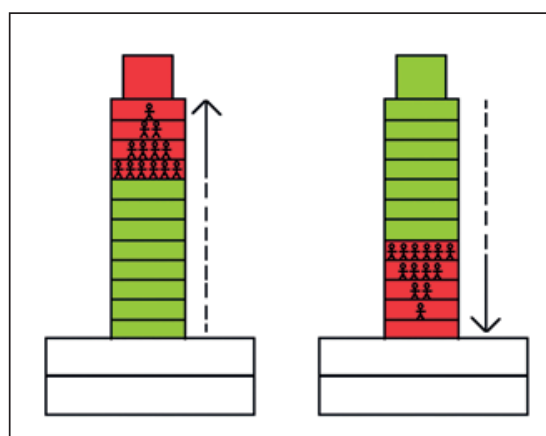

Figura 3

Planejamento de baixo para cima ou de cima para baixo

do nível da rua, pois o investidor teria 9.457,04 $\mathrm{m}^{2}$ a comercializar.

Após a análise de $\mathrm{CH} \times \mathrm{CV}$, a Estrutura de Concreto e Contenção foi ajustada para $21 \%$ de construção abaixo do nível da rua, ou seja 4.481,63 $\mathrm{m}^{2}$ a comercializar. Neste caso, o investidor está deixando de "ganhar" a diferença de 4.975,41 m²

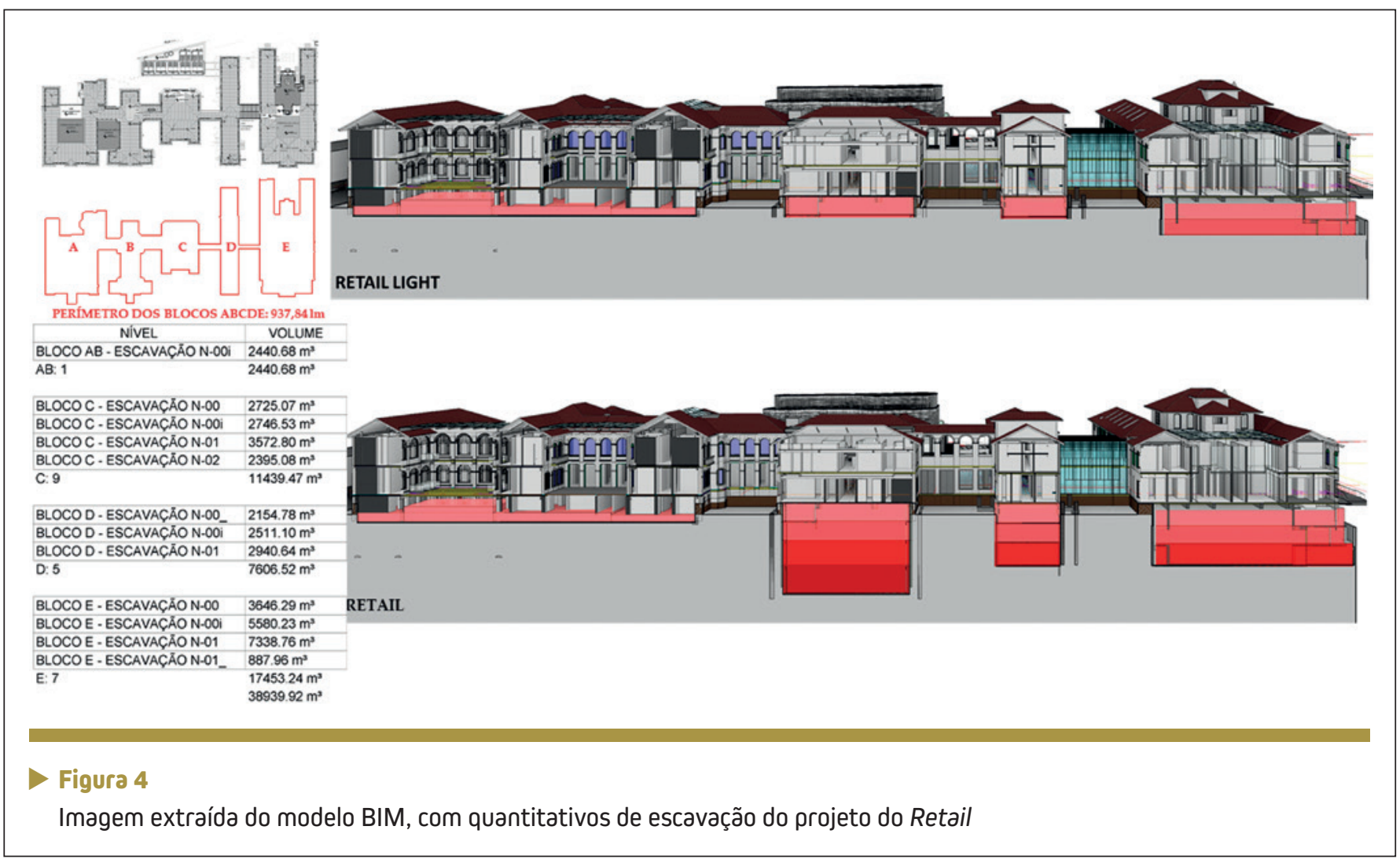


no seu empreendimento. O Investidor não entenderia com facilidade se isto não fosse devidamente customizado e justificado.

Na realidade, a análise de $\mathrm{CH}$ e CV absorveu a área de 4.975,41 m² de supostos ganhos, mas que seriam um investimento irrecuperável. A área a ser construída seria muito onerosa e o retorno do investidor se estenderia por muitos anos.

Uma decisão pautada em soluções de projeto evita a gestão de autopsias que frequentam, infelizmente, o mercado de construção. Cria-se uma solução sem a devida análise de custo e, ao ficar pronta, não há retorno do investimento, gastando-se mais que o necessário em termos de negócio, de futuro ganho.

\section{ANÁLISE DE CH E CV EM SOLUÇÕES LOGÍSTICAS}

Custos Verticais são quantitativamente fundamentais para dimensionamentos logísticos, e, no caso real em questão (Figura 5a e 5b), considerando-se os equipamentos de transporte vertical e horizontal, observamos seus impactos na gestão de gargalos, que, de forma antecipada, evita que o $\mathrm{CH}$ habitualmente usado leve a enganos de prazo e custo.

Nota-se que a relação de paredes nos andares mais baixos é de $1,5 \mathrm{~m}^{2}$ vertical para cada 1,0 $\mathrm{m}^{2}$ horizontal (Figura 5a)

Nos andares mais altos, a relação foi de $0,54 \mathrm{~m}^{2}$ vertical para cada 1,0 $\mathrm{m}^{2}$ horizontal, dado o menor adensamento de paredes (Figura 5b).

A velocidade de equipamento paleteiras horizontais é de $33 \mathrm{~m} / \mathrm{min}$, aproximadamente $2 \mathrm{~km} / \mathrm{h}$, e a do equi-

Tabela 1 - Tabela de áreas acima e abaixo do térreo

\begin{tabular}{|c|cc|}
\hline Tabelas de áreas & Projeto versão 1 & Novo projeto \\
\hline & $1.135,06$ & $1.081,11$ \\
\hline Área dos subsolos & $1.135,06$ & $1.432,80$ \\
\hline & $1.135,06$ & $4.122,22$ \\
\hline Área dos térreos & $1.376,45$ & $2.821,11$ \\
\hline e níveis superiores & $0,37 \pm 0,03$ & $4.639,54$ \\
\hline & $0,44 \pm 0,09$ & $6.660,82$ \\
\hline & $0,37 \pm 0,03$ & $5.433,59$ \\
\hline
\end{tabular}

Tabela 2 - Tabela resumo de áreas acima e abaixo do térreo

\begin{tabular}{|ccc|}
\hline Tabelas de áreas & Projeto versão 1 & Novo projeto \\
\hline Área dos subsolos & $4.781,63$ & $9.457,04$ \\
\hline Área dos térreos & $17.783,00$ & $18.891,59$ \\
\hline e níveis superiores & $22.564,63$ & $28.348,63$ \\
\hline Área total de projeto & & \\
\hline
\end{tabular}

Tabela 3 - Tabela de índice entre área abaixo e acima do térreo

\begin{tabular}{|ccc|}
\hline Índice de área construída & Projeto versão 1 & Novo projeto \\
\hline Área dos subsolos & $4.781,63$ & $9.457,04$ \\
\hline Área total de projeto & $22.564,63$ & $28.348,63$ \\
\hline Índice de área horizontal & 0,21 & 0,33 \\
\hline
\end{tabular}

Tabela 4 - Tabela de altura média abaixo do térreo

\begin{tabular}{|ccc|}
\hline Análise vertical & Projeto versão 1 & Novo projeto \\
\hline Área vertical de contenção & $4.157,00$ & $9.596,00$ \\
\hline Perímetro de todos os blocos & 937,84 & 937,84 \\
\hline $\begin{array}{c}\text { Altura média até 0 } \\
\text { último nível de subsolo }\end{array}$ & 4,43 & 10,23 \\
\hline
\end{tabular}

pamento cremalheira de transporte vertical é de $30 \mathrm{~m} / \mathrm{min}$ (Figura 6)

As distâncias horizontais e verticais analisadas apresentam um fator de 1,3 no grau de dificuldade para andares altos, sendo que o $\mathrm{CV} \times \mathrm{CH}$ foi analisado em separado, permitindo a gestão de custos e prazos.
As Figuras 7 e 8 apresentam a análise da Curva de Aprendizado após a avaliação do $\mathrm{CH}$ e do CV.

\section{ANÁLISE DE CH E CV NA VALORIZAÇÃO DE MEMORIAL DESCRITIVO}

A venda de imóveis, em geral, 


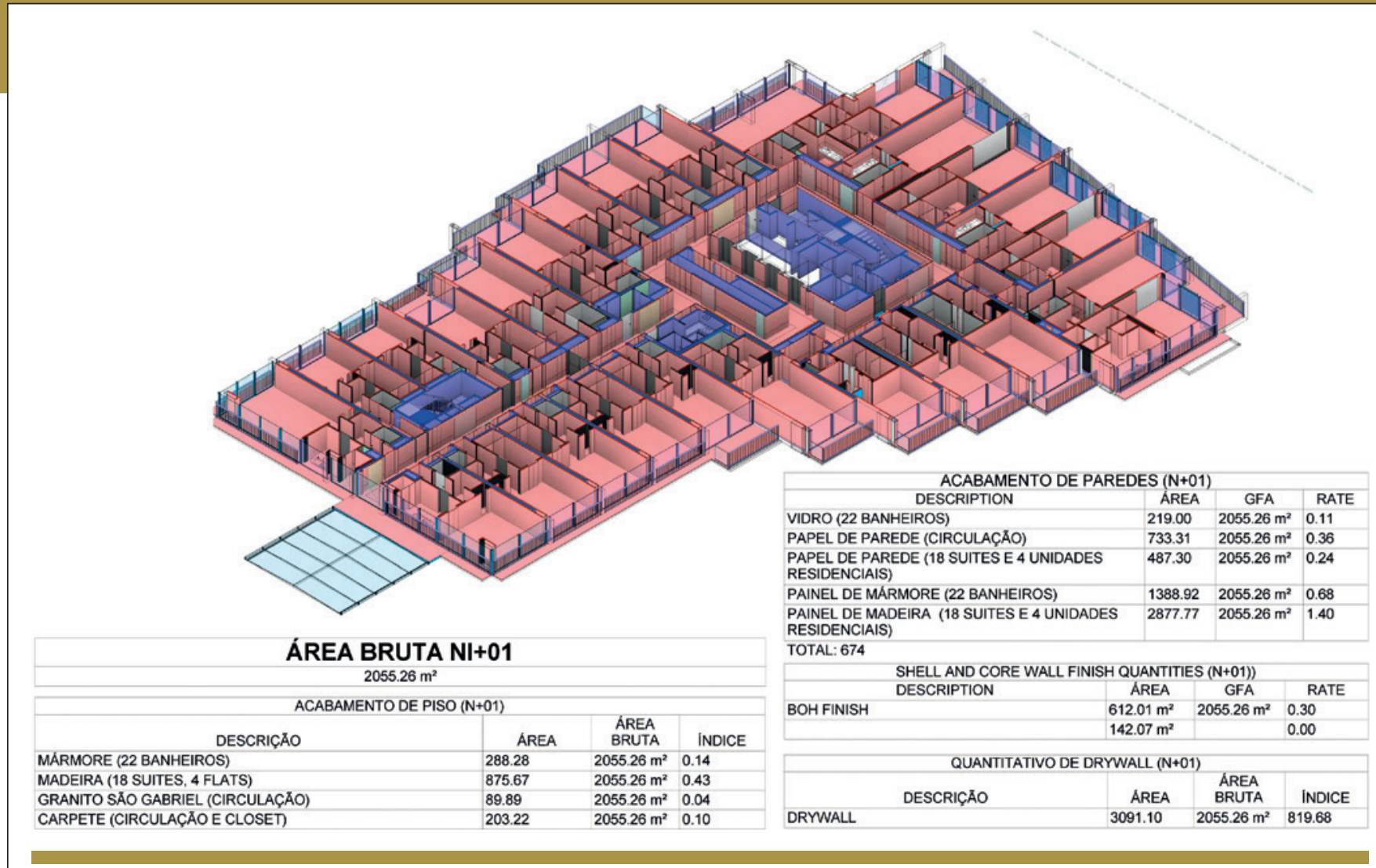

\section{Figura 5 a}

Extração de quantitativo de acabamentos de piso e parede com índices baseados na área bruta

Fonte: Cidade Matarazzo, 2020

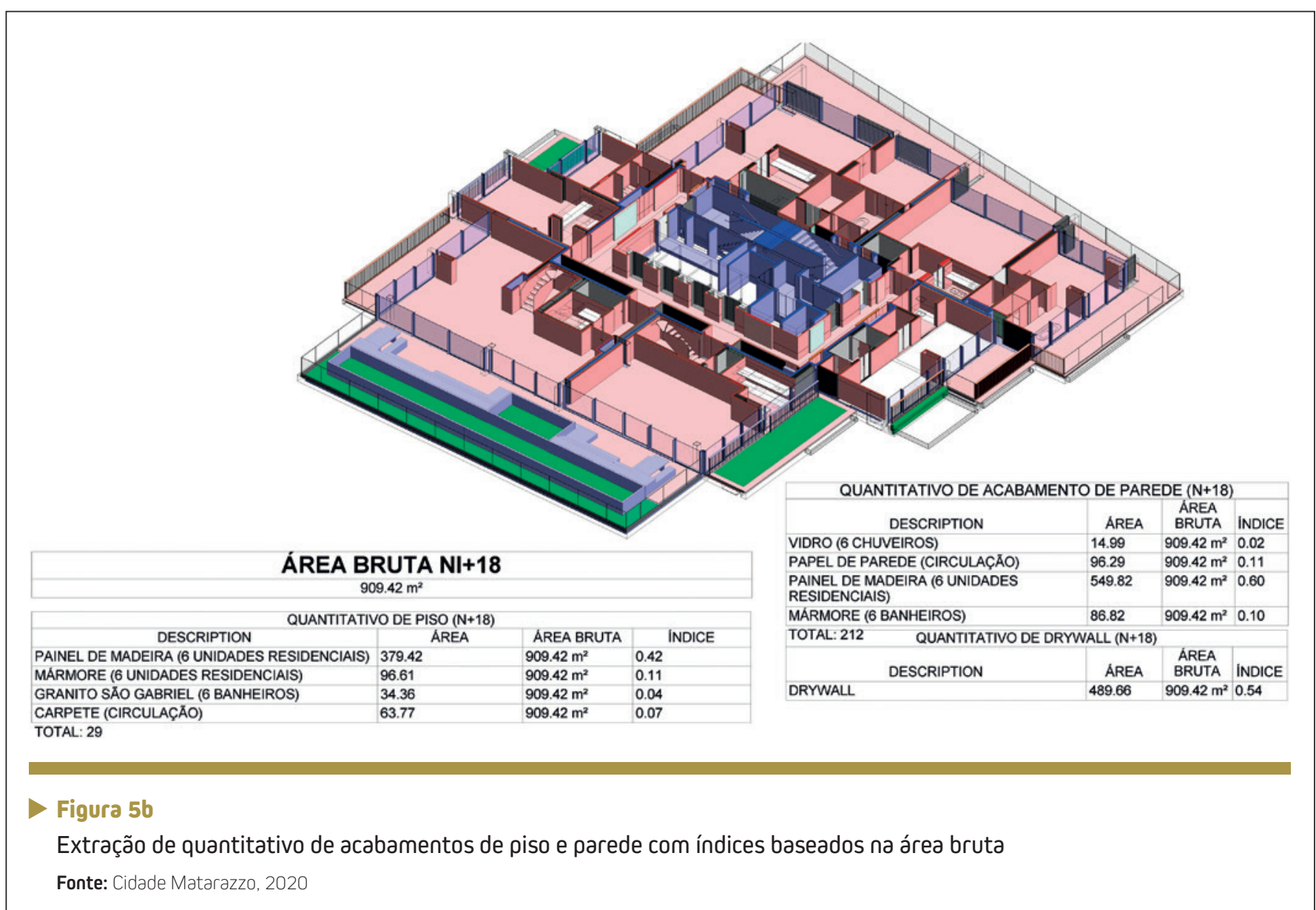


DEFINIÇÃO DAS TAXAS DE CADA FATOR NOS PRAZOS DAS ATIVIDADES:

VX | DESLOCAMENTO HORIZONTAL - TRANSPORTE EM PALETEIRAS $33,4 \mathrm{~m} / \mathrm{min}(2 \mathrm{~km} / \mathrm{h})$

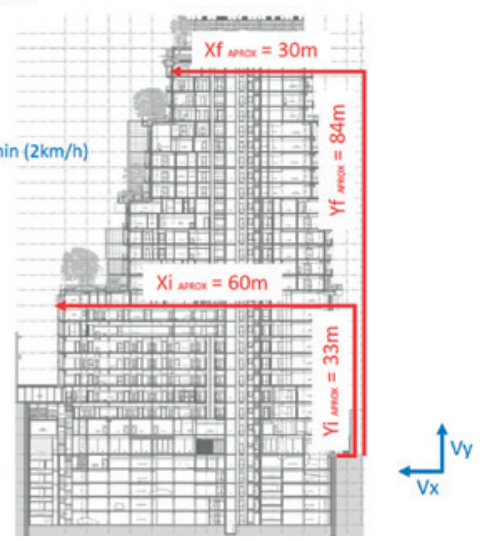

Figura 6

Corte com distâncias horizontais e verticais aproximadas e cálculo da taxa logística da torre

baseia-se no preço do metro quadrado do bairro, por metro quadrado horizontal, sem outros méritos, que passam despercebidos pelos que compram e pelos que vendem.

A análise de $\mathrm{CH}$ e $\mathrm{CV}$ permite que sejam valorizados os produtos e, por consequência, a sua vida útil, parâmetro que passou a considerado pela grande maioria de compradores do mercado após a publicação da Norma de Desempenho.
O exemplo apresentado na Figura 8 foi usado para a definição de acabamentos de um produto. Cada prédio teve a análise de sua relação de áreas $\mathrm{H}$ e V.

Num estudo, a área vertical é 1,1 vezes a área horizontal. No outro, a área vertical é 3,5 vezes a área horizontal.

A escolha de mesmo Memorial para pisos e paredes levaria ambas as obras a terem aparentemente as mesmas áreas horizontais e seus custos seriam o dobro uma da outra. O conceito de $\mathrm{CH}$ e $\mathrm{CV}$ é fundamental para a tomada de decisão e avaliação de produtos.

Um produto vendido no mercado por $\mathrm{R} \$ 40.000 / \mathrm{m}^{2}$ é mais caro que um produto vendido no mercado a $\mathrm{R} \$$ $27.000 / \mathrm{m}^{2}$ ? Nem sempre, basta seu custo vertical estar diferente, pois no custo horizontal dificilmente manifestam-se grandes diferenças. Quando se oferta a mercado um produto a $\mathrm{R} \$$ 40 mil por metro quadrado e um produto ofertado a $\mathrm{R} \$ 27$ mil por metro quadrado, ambos com a mesma área horizontal, o produto de $\mathrm{R} \$ 40$ mil por metro quadrado pode mais barato que o de $R \$ 27$ mil por metro quadrado, basta avaliar o memorial utilizado no custo vertical.

A análise da Figura 7 avalia duas soluções em que os índices de custo horizontal e vertical definem duas direções de escolha pautada em custo $\mathrm{H}$ e V.

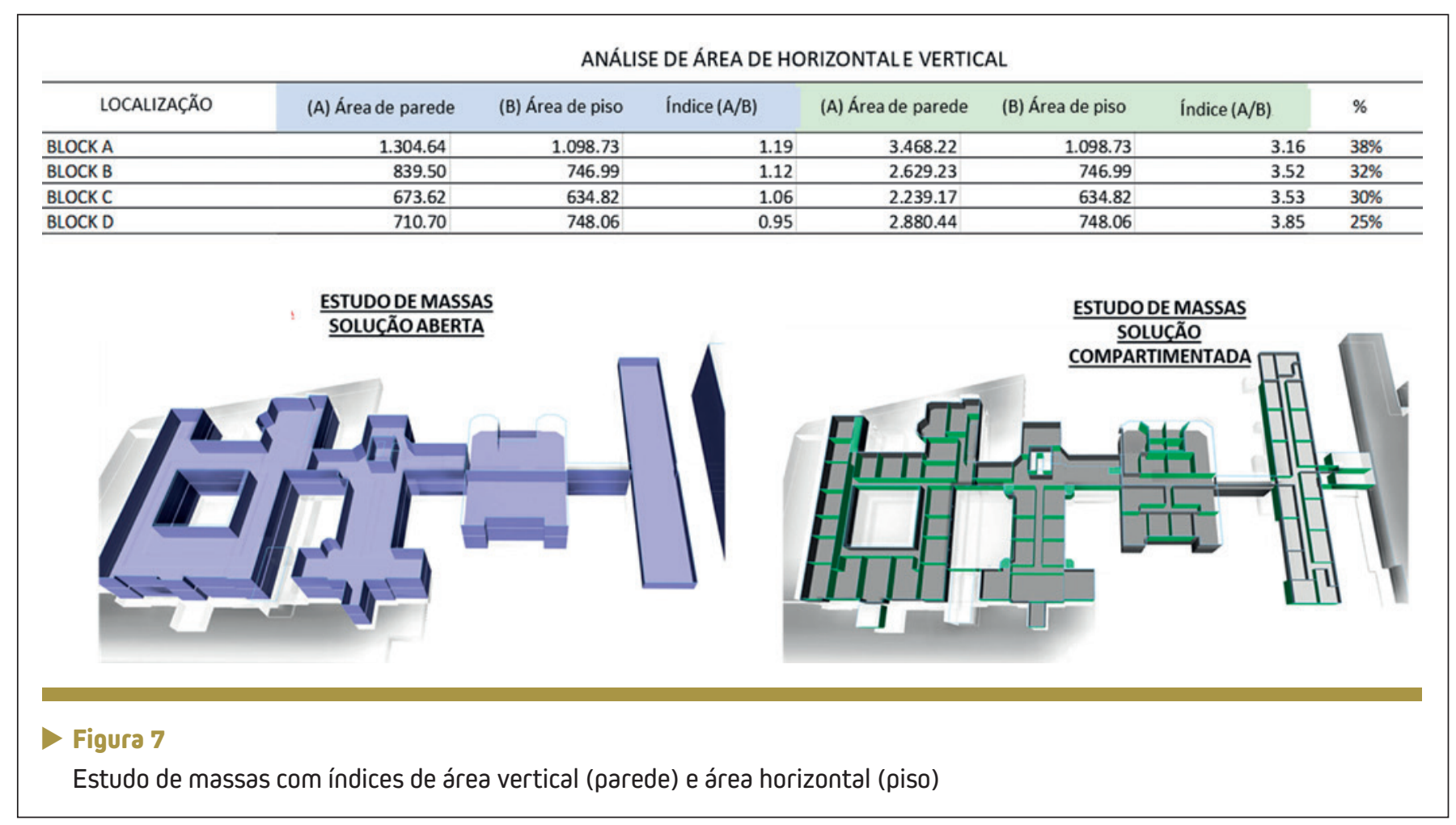


1) IDENTIFICAÇÃO DOS FATORES QUE COMPÕEM A CURVA DE APRENDIZADO:

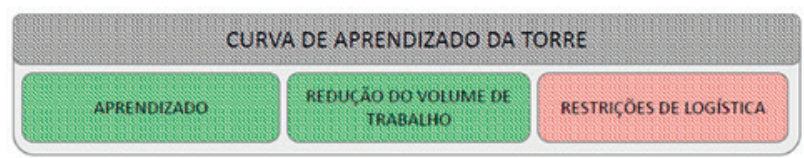

2) DEFINIÇÃO DAS TAXAS DE CADA FATOR NOS PRAZOS DAS ATIVIDADES:

\% VOLUME DE TRABALHO
$\%$ LOGISTICA

\% APRENDIZADO

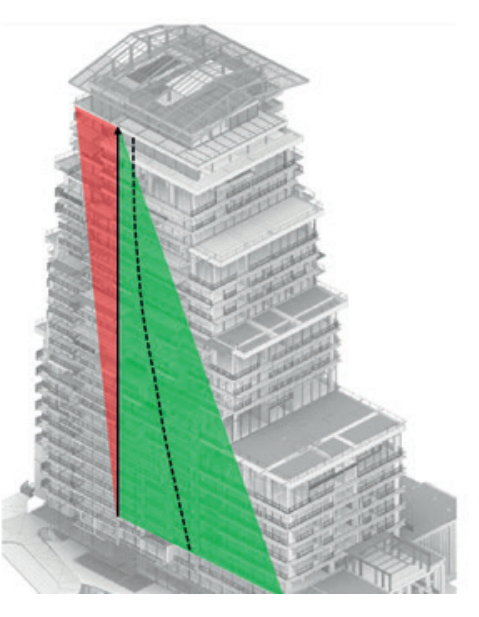

SHELLAND CORE N-18

5 MESES

ESTABELECIMENTODO PADRÃo PARA RESULTADO DA CURVA DE APRENDIZADO

PERFORMANCE DAS ATIVIDADES CONFORME CURVA DE APRENDIZADO

SHEL AND COREN-1.

8 MESES

\section{Figura 8}

Diagrama de curva de curva de aprendizado

\section{CONCLUSÃO}

A comunidade cientifica, a Academia, os sindicatos patronais têm se colocado à disposição do desenvolvimento.

Após anos de trabalhos acadêmicos e de desenvolvimento de sistemas por alguns idealistas de mercado, atingimos um novo patamar, mas ainda distante de um vasto aproveitamento de recursos e pesquisas disponíveis.
A implantação de um mercado mais assertivo, controlado pelo BIM e outras ferramentas de gestão, da customização Vertical e Horizontal , de Soluções de Engenharia, ajudará a reduzir as surpresas dos investidores, mantendo seus planos de investimento, manterá a margem de lucro dos construtores, beneficiará os consumidores com produtos conformes e duráveis, reduzirá os aditivos e ex- cessos nos contratos com o Governo (Figuras 9 e 10).

A análise dos impactos do Custo Vertical e Horizontal precisa fazer parte de nosso planejamento, evitando-se surpresas futuras e inoportunas que geram atrasos e prejuízos em obras.

Fazer certo custa menos que fazer errado, basta saber antes o que pode ocorrer, fugindo da mencionada Gestão de Autopsia mercadológica.

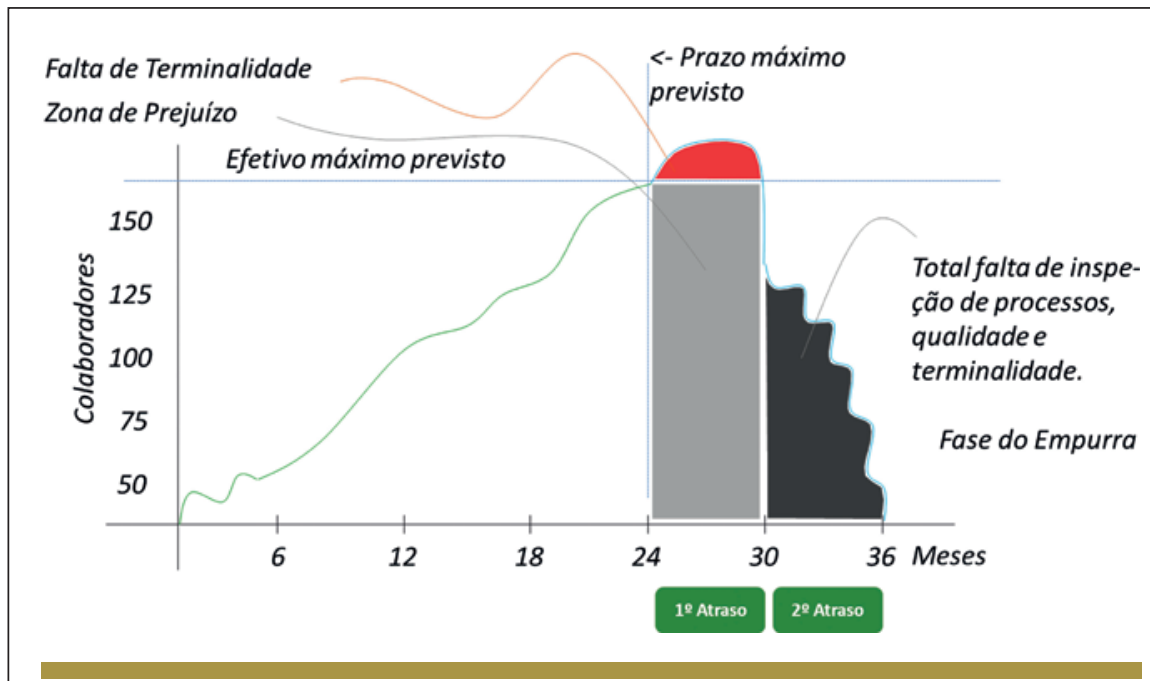

Figura 9

Diagrama de terminalidade
Fluxo para reconhecer a importância do CV e CH em nossa decisões

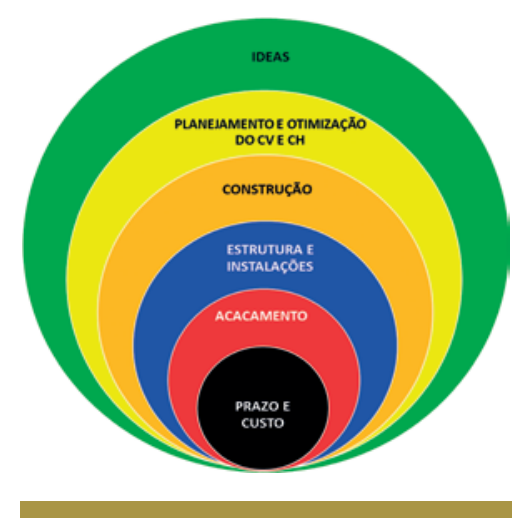

Figura 10

Matriz de importância do custo vertical e custo horizontal

\section{DREFERENCIAS BIBLIOGRÁFICAS}

[1] Programa de Terminalidade do Autor.

[2] Empreendimento Cidade Matarazzo.

[3] Levantamentos da RM+System. 